\title{
The social structure of microbial community involved in colonization resistance
}

\author{
Xuesong He, Jeffrey S McLean, Lihong Guo, Renate Lux and Wenyuan Shi
}

The ISME Journal (2014) 8, 2352; doi:10.1038/ismej.2014.109

Correction to: The ISME Journal (2014) 8, 564-574; doi:10.1038/ismej.2013.172; published online 3 October 2013

Since the publication of this article, the authors have identified an omission in the 'Conflict of Interest' section. The missing statement is as follows:
Dr Wenyuan Shi is a part time Chief Science Officer of C3 Jian Inc., which has licensed technologies from UC Regents that could be indirectly related to this research project.

The authors would like to apologize for any inconvenience this may have caused.

\section{Microorganisms persist at record depths in the subseafloor of the Canterbury Basin}

Maria-Cristina Ciobanu, Gaëtan Burgaud, Alexis Dufresne, Anja Breuker, Vanessa Rédou, Sarah Ben Maamar, Frédéric Gaboyer, Odile Vandenabeele-Trambouze, Julius Sebastian Lipp, Axel Schippers, Philippe Vandenkoornhuyse, Georges Barbier, Mohamed Jebbar, Anne Godfroy and Karine Alain

The ISME Journal (2014) 8, 2352; doi:10.1038/ismej.2014.110

Correction to: The ISME Journal (2014) 8, 1370-1380; doi:10.1038/ismej.2013.250; published online 16 January 2014

Since the publication of this article, it has come to the authors' attention that the study accession number deposited in the Sequence Read Archive was omitted from the article. The study accession number is ERP002102.

The Authors would like to apologise for any inconvenience this may have caused. 